\title{
Expanding the field of cold snare polypectomy
}

Authors

Institutions
Lobke Desomer ${ }^{1}$, Michael J. Bourke ${ }^{1,2}$

${ }^{1}$ Department of Gastroenterology and Hepatology, Westmead Hospital, Sydney, Australia

${ }^{2}$ Westmead Clinical School, University of Sydney, Sydney, Australia

\section{Bibliography}

DOI http://dx.doi.org/

10.1055/s-0034-1393088

Published online: 6.10.2015

Endoscopy International Open

2015; 03: E514-E515

(c) Georg Thieme Verlag KG

Stuttgart · New York

E-ISSN 2196-9736

\section{Corresponding author \\ Michael J. Bourke}

Department of

Gastroenterology and

Hepatology

Westmead Hospital

c/-Suite 106a

151 - 155 Hawkesbury Road

Westmead

Sidney

New South Wales, 2143

Australia

michael@citywestgastro.com. au

\section{License terms}

(ब) (1) $\ominus$
Endoscopic mucosal resection (EMR) is now a widely accepted and well described technique for the removal of large laterally spreading lesions (LSL) in both the colon and duodenum $[1,2]$. Specific aspects of the technique may differ but the general principles are the same. After submucosal injection with a variety of dye-containing solutions, the lesion is removed by sequential snare resections with diathermy. High-volume, prospective multicenter data show that most LSL in the colon can safely and effectively be treated by EMR $[2,3]$.

The most feared complications of EMR of large LSL are perforation and bleeding, both of which are mostly derived from diathermy. Intraprocedural bleeding occurs in $10 \%$ to $15 \%$ but is generally easily treated without sequelae and most conveniently with snare tip soft coagulation (STSC) [4]. Perforation or deep mural injury is usually recognized intraprocedurally [5] and subsequently closed using clips. Surgery for perforation is now quite uncommon. Two major problems persist: recurrence and clinically significant post-EMR bleeding (CSPEB). As resection and imaging techniques are improving, the frequency of residual adenoma is falling and is now approximately $15 \%$ [2,3]. Even so, this seems to be of little clinical consequence as recurrence is usually diminutive and easily managed endoscopically, rendering patients disease-free in long-term follow-up [3]. However, CSPEB remains a major issue occurring with a frequency of $6 \%$ overall after EMR of LSL in the colon and up to $12 \%$ in the right colon [6]. The risk is even greater in the duodenum at approximately $25 \%$ for giant duodenal adenomas [7]. An effective method of preventing this has yet to be found; therefore, it seems acceptable to explore the field of cold snare polypectomy (CSP) for the removal of large LSL to minimize the risk of delayed bleeding. Furthermore, transection of the muscular propria using a cold snare is probably impossible and so, the risk of perforation is also reduced with CSP.

CSP has proven to be a safe and effective technique for removal of diminutive polyps in the colon [8]. However, duodenal polyps represent a completely different group due to the physiologic and anatomic differences as compared to the colon. The thin muscular layer of the duodenal wall in combination with the rich vascularisation makes the duodenum particularly prone to these complications ( $\nabla$ Fig. 1).

The pilot study of Choksi et al. [9] is interesting because the authors have tried to combine the best of both worlds. A well-formed cushion after submucosal injection, applied in the majority of the duodenal lesions, elevates the mucosa away from the larger submucosal vessels where most of the bleeding risk is believed to arise. Combined with the absence of diathermy, this may decrease the risk of delayed bleeding, because this likely relates to thermal injury to submucosal vessels. In this retrospective study, 15 patients (mean age 64 years, mean lesion size $24 \mathrm{~mm}$, range $10-60$ $\mathrm{mm}$ ) with a duodenal polyp were included. Several types of snares and cold biopsy forceps were used to aid in resecting residual tissue at the defect base and edge. There were no perforations. Immediate bleeding, although not defined, was reported in two patients and hemostatic clips were used to control the bleeding. Delayed bleeding after 7 days (CSPEB), requiring hospitalization and endoscopic hemostasis, occurred in one patient on warfarin.

Beyond safety, efficacy is also important and complete removal of the polyp is paramount to avoid recurrence or interval cancer $[10,11]$. The Complete Adenoma Resection (CARE) study has shown that in the case of CSP, colonic polyps are incompletely removed in $6.8 \%$ of patients [12]. With cold forceps biopsy, this increases to nearly $30 \%[12,13]$. It is unclear however, whether these results can be extrapolated to duodenal polyps. In 


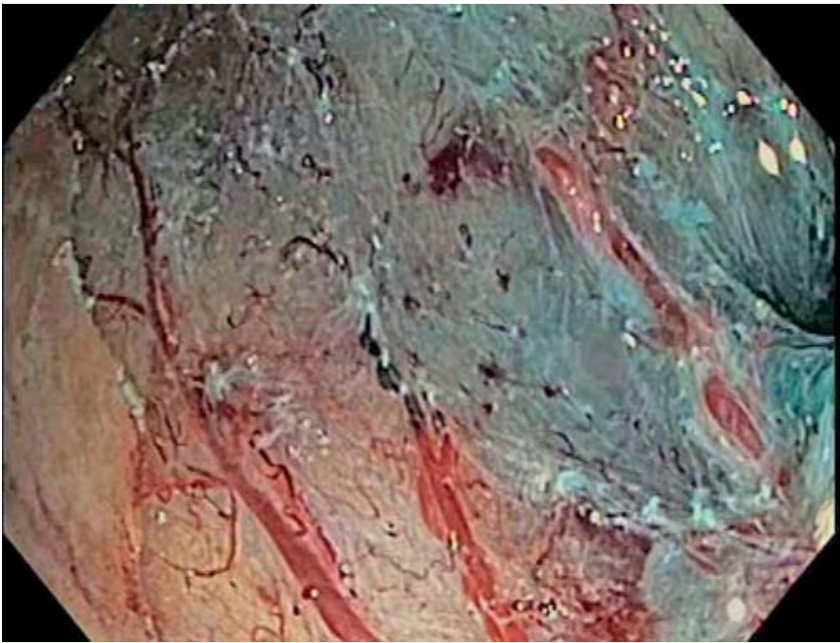

Fig. 1 Post-EMR defect site showing the rich duodenal vascularisation.

the study by Choksi et al., the majority of resection sites were also treated with cold forceps biopsy until macroscopic complete removal was assured. Does this technique achieve complete adenoma excision? Based on the existing evidence, that would seem unlikely. Thus follow-up data will be very important. However, it must be borne in mind that even in the event of recurrence, scheduled, programmatic follow-up is usually sufficient to treat the recurrence and avoid long-term sequelae [3].

The type of snare may play an important role here. A recent study by Horiuchi et al. has shown the superiority of a thin wire snare dedicated for CSP over a conventional snare for the complete removal of colorectal polyps [14]. In this current study, a thin wire snare also was used, as well as other types of snares. Because there is no information on recurrence in this study, we might expect recurrence rates to be lower for polyps removed by a stiff, thin wire snare. Further study is necessary to confirm this. In conclusion, the field of CSP is increasingly being explored, because of its ease of use and low rate of complications. This pilot study has shown an acceptable safety profile but bleeding remains the most important complication and has not been eliminated using the cold snare technique. Furthermore, data on recurrence are lacking when this technique is used for piecemeal resection and should be addressed. Large, preferably multicenter, prospective, randomized controlled trials are necessary to answer these important questions.

\section{Competing interests: None}

\section{References}

1 Bourke M. Endoscopic mucosal resection in the colon: A practical guide. Tech Gastrointest Endosc 2011; 13: 35 - 49

2 Moss A, Bourke MJ, Williams SJ et al. Endoscopic mucosal resection outcomes and prediction of submucosal cancer from advanced colonic mucosal neoplasia. Gastroenterology 2011; 140: 1909-1918

3 Moss A, Williams SJ, Hourigan LF et al. Long-term adenoma recurrence following wide-field endoscopic mucosal resection (WF-EMR) for advanced colonic mucosal neoplasia is infrequent: results and risk factors in 1000 cases from the Australian Colonic EMR (ACE) study. Gut 2015; 64: 57-65

4 Fahrtash-Bahin F, Holt BA, Jayasekeran Vet al. Snare tip soft coagulation achieves effective and safe endoscopic hemostasis during wide-field endoscopic resection of large colonic lesions (with videos). Gastrointest Endosc 2013; 78: 158-163.e1

5 Swan MP, Bourke MJ, Moss A et al. The target sign: an endoscopic marker for the resection of the muscularis propria and potential perforation during colonic endoscopic mucosal resection. Gastrointest Endosc 2011; 73: 79-85

6 Burgess NG, Metz AJ, Williams SJ et al. Risk factors for intraprocedural and clinically significant delayed bleeding after wide-field endoscopic mucosal resection of large colonic lesions. Clin Gastroenterol Hepatol 2014; 12: 651-661

7 Fanning SB, Bourke MJ, Williams SJ et al. Giant laterally spreading tumors of the duodenum: endoscopic resection outcomes, limitations, and caveats. Gastrointest Endosc 2012; 75: 805-812

8 Repici A, Hassan C, Vitetta E et al. Safety of cold polypectomy for <10mm polyps at colonoscopy: a prospective multicenter study Endoscopy 2012; 44: 27-31

9 Choksi N, Elmunzer B, Stidham R et al. Cold-Snare Piecemeal Resection of Colonic and Duodenal Polyps $>1 \mathrm{~cm}$. Endosc Int Open 2015

10 Zauber AG, Winawer SJ, O'Brien MJ et al. Colonoscopic Polypectomy and Long-Term Prevention of Colorectal-Cancer Deaths. N Engl J Med 2012; 366: 687-696

11 Kahi CJ, Imperiale TF, Juliar BE et al. Effect of screening colonoscopy on colorectal cancer incidence and mortality. Clin Gastroenterol Hepatol 2009; 7: 770 - 775

12 Pohl H, Srivastava A, Bensen SP et al. Incomplete polyp resection during colonoscopy - Results of the complete adenoma resection (CARE) study. Gastroenterology 2013; 144: 74-80.e1

$13 \mathrm{Kim}$ JS, Lee B, Choi $\mathrm{H}$ et al. Cold snare polypectomy versus cold forceps polypectomy for diminutive and small colorectal polyps : a randomized controlled trial. Gastrointest Endosc 2015; 81: 741 - 747

14 Horiuchi A, Hosoi K, Kajiyama $M$ et al. Prospective, randomized comparison of 2 methods of cold snare polypectomy for small colorectal polyps. Gastrointest Endosc 2015: In press. 